\title{
Correction to: Diverse Polyphenols from Hypericum faberi
}

\author{
Xin-Wen Zhang ${ }^{1,2} \cdot$ Yan-Song Ye ${ }^{1,2} \cdot$ Fan Xia ${ }^{1} \cdot$ Xing-Wei Yang ${ }^{1} \cdot$ Gang Xu ${ }^{1}$
}

Published online: 5 August 2019

(c) The Author(s) 2019

\section{Correction to:}

Natural Products and Bioprospecting (2019) 9:215-221

https://doi.org/10.1007/s13659-019-0206-1

In the original publication the corresponding author appeared incorrectly as Xin-Wen Zhang.

The corrected text is given below:

The corresponding author of the article is Gang Xu.
Open Access This article is distributed under the terms of the Creative Commons Attribution 4.0 International License (http://creativecommons.org/licenses/by/4.0/), which permits unrestricted use, distribution, and reproduction in any medium, provided you give appropriate credit to the original author(s) and the source, provide a link to the Creative Commons license, and indicate if changes were made.

Publisher's Note Springer Nature remains neutral with regard to jurisdictional claims in published maps and institutional affiliations.

The original article can be found online at https://doi.org/10.1007/ s13659-019-0206-1.

\section{Gang Xu}

xugang008@mail.kib.ac.cn

1 State Key Laboratory of Phytochemistry and Plant Resources in West China, Kunming Institute of Botany, Chinese Academy of Sciences, Yunnan Key Laboratory of Natural Medicinal Chemistry, Kunming 650201, People's Republic of China

2 University of Chinese Academy of Sciences, Beijing 100049, People's Republic of China 